\title{
Gene expression alterations in inflamed and unaffected colon mucosa from patients with mild inflammatory bowel disease
}

\author{
LILI XU ${ }^{1}$, LILI MA ${ }^{2}$, JINGJING LIAN ${ }^{2}$, JIAYIN YANG ${ }^{1}$ and SHIYAO CHEN ${ }^{1,2}$ \\ ${ }^{1}$ Division of Gastroenterology; ${ }^{2}$ Endoscopy Center, Zhongshan Hospital, Fudan University, Shanghai 200032, P.R. China
}

Received March 30, 2015; Accepted January 13, 2016

DOI: $10.3892 / \mathrm{mmr} .2016 .4880$

\begin{abstract}
An endoscopic examination is currently the most reliable method for monitoring disease activity in patients with inflammatory bowel disease (IBD). However, endoscopic evaluations are unable to detect mucosal inflammation at the earliest stages. The present study aimed to evaluate the molecular profiles of inflamed and unaffected colon mucosa from patients with mild Crohn's disease (CD) and ulcerative colitis (UC), in order to identify a more sensitive method for monitoring mucosal impairment. Patients were recruited and colon biopsies from the inflamed and the normal-appearing mucosa of patients with mild IBD were obtained by colonoscopy. Gene expression analysis was performed using microarrays, after which Gene Ontology and clustering were performed using bioinformatics. In addition, the levels of inflammatory cytokines were analyzed by reverse transcription-quantitative polymerase chain reaction. A total of 620 genes in the inflamed and 210 genes in the unaffected colon mucosa with at least a 3 -fold change, as compared with healthy controls, were detected in patients with mild $\mathrm{CD}$, and 339 genes in the inflamed and 483 genes in the unaffected colon mucosa were detected in patients with mild UC. Heat mapping demonstrated a similarity in the gene alteration patterns, and altered transcripts overlapped, between the inflamed and unaffected colon mucosa. Interferon- $\gamma$ and interleukin-17 mRNA levels were comparably elevated in the inflamed and unaffected colon mucosa from patients with IBD. Marked gene expression alterations were detected in the inflamed and unaffected colon mucosa from patients with mild IBD, and these showed marked similarity and overlap between the two groups. The results of the
\end{abstract}

Correspondence to: Professor Lili $\mathrm{Xu}$, Division of Gastroenterology, Zhongshan Hospital, Fudan University, 180 Fenglin Road, Shanghai 200032, P.R. China

E-mail: xu.lili3@zs-hospital.sh.cn

Professor Shiyao Chen, Endoscopy Center, Zhongshan Hospital, Fudan University, 180 Fenglin Road, Shanghai 200032, P.R. China E-mail: chen.shiyao@zs-hospital.sh.cn

Key words: gene expression profile, mucosa inflammation, inflammatory bowel diseases, microarray present study suggested that inflammation was not limited to the endoscopic lesions and that gene expression profiling may be considered a sensitive tool for monitoring mucosal inflammation, predicting relapses and optimizing therapeutic strategies for patients with IBD.

\section{Introduction}

Inflammatory bowel disease (IBD), which is an umbrella term for a collection of diseases that include Crohn's disease (CD) and ulcerative colitis (UC), is characterized by flares and periods of remission (1). The clinical course of IBD is quite variable; however, $\geq 35 \%$ of patients receiving standardized care experience relapse and $15 \%$ ultimately do not respond to medical therapy (1). These varied outcomes are likely due to genetic, microbial and immune heterogeneity, as well as treatment strategies and lifestyle factors (2-4). Disease relapses decrease the quality of life of affected individuals. In the last few decades, studies have focused on the identification of possible factors, including the neutrophil $\mathrm{Fc} \gamma$ receptor I (CD64) index, anti-GM-CSF antibody (Ab) levels, serum levels of ficolin-2, fecal calprotectin and Clostridium difficile presence, that may correlate with disease activity and predict disease relapse (5-10). However, to the best of our knowledge, none of the previously investigated factors were found to be reliable indicators of disease activity. Once endoscopic remission has been achieved, it is difficult for a physician to identify the optimum point for ceasing or tapering IBD medication; previous studies demonstrated that mucosal healing could not predict sustained remission in patients with IBD following discontinuation of infliximab therapy or thiopurine withdrawal (11-13).

At present, disease activity is assessed on the basis of a clinical evaluation and endoscopic examination (11-13). Initiating 'top down' biological treatment immediately following surgery, rather than waiting for disease recurrence, has been shown to provide the best rates of long-term prevention (14); thus indicating that underlying mucosal inflammation may be present even following complete endoscopic remission. A previous study demonstrated that some patients exhibit endoscopic recurrence and yet require re-resection within 1 year of the initial surgical resection of lesions (13). Therefore, a reliable method for the diagnosis of mucosal inflammation is required in order to allow preventative medication to be initiated prior to the development of irreversible intestinal 
damage (15). Such a diagnostic tool would enable patients to be treated at the earliest signs of disease onset. At present, endoscopy is the most sensitive method for detecting early mucosal changes; a severe endoscopic recurrence at 1 year was shown to predict a clinical relapse (16). However, in some cases, the severity of an endoscopic lesion does not always match the clinical manifestations; it was previously shown that certain patients with mild IBD had a poor response to treatment and in some cases the disease quickly relapsed during tapering or withdrawal of medication despite evidence of endoscopic remission $(15,16)$. Therefore, it is possible that the remission assessed by clinical and endoscopic evaluation was incomplete in these cases. Thus, a clinical relapse is typically assessed based on the clinical activity index (CAI) (17), or the Crohn's Disease Activity Index (CDAI) (18), rather than on the endoscopic findings.

The present study analyzed the gene expression profiles of inflamed and unaffected colon mucosa from patients with mild CD and UC, in order to establish a more sensitive method for monitoring mucosal impairment.

\section{Materials and methods}

Patients. A total of 24 patients with IBD (13 men and 11 women; mean age, $41 \pm 15$ years) visiting the Outpatient Clinic of Zhongshan Hospital (Shanghai, China) between July 2013 and September 2014 were enrolled in the present study. The disease activity was assessed based on CDAI for patients with $\mathrm{CD}$ and CAI for patients with UC, and the severity of the lesion was determined based on endoscopic findings. The assessed lesions were limited to the sigmoid colon and rectum of all patients. The group with mild CD consisted of 8 patients with a CDAI between 150 and 220. The mild UC group consisted of 16 patients with a CAI between 4 and 5 . A total of 5 patients with $\mathrm{CD}$ and 10 patients with UC were undergoing treatment with 5-aminosalicylic acid prior to and during the present study. As a control group, 9 healthy subjects, including 5 men and 4 women (mean age, $46 \pm 10$ years) without a history of IBD or other known chronic diseases, were enrolled in the present study. All colon biopsies were collected via a colonoscopy and were immediately stored in RNAlater (Qiagen GmBH, Mannheim, Germany). The present study was approved by the Ethical Committee of Medical Research, Zhongshan Hospital, Fudan University. Informed consent was obtained from all patients.

RNA extraction and purification. Colon biopsy specimens were homogenized and total RNA was extracted using TRIzol $^{\circledR}$ reagent (Thermo Fisher Scientific, Inc., Waltham, MA, USA) according to the manufacturer's protocol. The RNA was checked for an RNA integrity number using an Agilent Bioanalyzer 2100 (Agilent Technologies, Santa Clara, CA, USA). Qualified total RNA was further purified using the RNeasy micro kit (Qiagen $\mathrm{GmBH}$ ) and RNase-Free DNase set (Qiagen $\mathrm{GmBH}$ ). Sample quality was assessed by a photospectrometer (Nano Drop Technologies, Thermo Fisher Scientific, Inc.). The 260/280 ratios in all samples were $>1.8$.

Microarray experiment. DNA microarrays (Affymetrix GeneChip Human Transcriptome Array 2.0; Affymetrix, Santa Clara, CA, USA) were performed according to the manufacturer's protocol. Briefly, total RNA was amplified, labeled with biotin and purified using the GeneChip ${ }^{\circledR}$ WT PLUS Reagent kit (cat. no. 902280; Affymetrix). Hybridization to the array and washing was performed with the GeneChip ${ }^{\circledR}$ Hybridization, Wash, and Stain kit (cat. no. 900720; Affymetrix) in a Hybridization Oven 645 and a Fluidics Station 450 (both Affymetrix). The arrays were scanned using the GeneChip ${ }^{\circledR}$ Scanner 3000 (Affymetrix). GeneChip ${ }^{\circledR}$ Command Console ${ }^{\circledR}$ software (Affymetrix, Santa Clara, CA, US) was used to control the scanner and summarize probe cell intensity data (CEL file generation) with default settings and the raw data were normalized using Expression Console software 1.4.1 (both Affymetrix).

The GeneChip Human Transcriptome Array 2.0 array interrogates 44,699 well-annotated genes using $>6$ million distinct probes. The array was designed based on the Homo sapiens hg19 reference genome (http://hgdownload.soe. ucsc.edu/goldenPath/hg19/chromosomes/) using the following databases: RefSeq (http://www.ncbi.nlm.nih.gov/refseq/), Ensembl (http://www.ensembl.org/index.html), UCSC Genome Browser (including known genes and lincRNA transcripts; https://genome.ucsc.edu/), the Vertebrate Genome Annotation (Vega) database (http://vega.sanger.ac.uk/index. html), the Mammalian Gene Collection (v10; http://genecollections.nci.nih.gov/MGC/), NONCODE (www.noncode.org/), the Long Noncoding RNA Database (http://www.Incrnadb. org/) and the Human lincRNA Catalog (http://www.broadinstitute.org/genome_bio/human_lincrnas/).

Reverse transcription-quantitative polymerase chain reaction $(R T-q P C R)$. RNA ( $2 \mu \mathrm{g})$ extracted from colon biopsy specimens from patients with UC was reverse-transcribed to cDNA using the ReverTra Ace ${ }^{\circledR}$ qPCR RT kit (Toyobo Co., Ltd., Osaka, Japan), according to the manufacturer's protocol. Following first strand cDNA synthesis, the mix was stored at $-20^{\circ} \mathrm{C}$ in a freezer prior to PCR analysis. mRNA expression levels were determined by qPCR on an ABI 7500 system (Applied Biosystems; Thermo Fisher Scientific, Inc.) using SYBR Premix Ex Taq RT-PCR kit (Takara Bio Inc., Dalian, China), according to the manufacturer's protocol. The cycling conditions were as follows: $95^{\circ} \mathrm{C}$ for $30 \mathrm{sec}$, followed by 40 cycles at $95^{\circ} \mathrm{C}$ for $5 \mathrm{sec}$ and $60^{\circ} \mathrm{C}$ for $34 \mathrm{sec}$. The following primers were used: Interferon (IFN) $-\gamma$ forward, 5'-TCGGTA ACTGACTTGAATGTCCA-3' and reverse, 5'-TCGCTTCCC TGTTTTAGCTGC-3'; interleukin (IL)-17 forward, 5'-AGC GCAACATGACAGTGAAG-3' and reverse, 5'-GTGTAA TTCCAGGGGGAGGT-3'; and glyceraldehyde 3-phosphate dehydrogenase (GAPDH) forward, 5'-GGAGCGAGATCC CTCCAAAAT-3' and reverse, 5'-GGCTGTTGTCATACT TCTCATGG-3'. GAPDH was examined under identical conditions as an internal control to demonstrate the equivalence of the template. The expression levels of the transcripts were evaluated using the $2^{-\Delta \Delta \mathrm{Cq}}$ method (19) on an ABI 7500 system (Applied Biosystems; Thermo Fisher Scientific, Inc.).

Statistical analysis and bioinformatics. Alterations in gene expression were defined using a fold change cutoff of $\geq \pm 2$. Heat maps were generated using ggplot (http://ggplot.yhathq. $\mathrm{com} /$ ). Cluster analysis of differentially expressed genes was performed using Affymetrix Transcriptome Analysis Console 
$\mathbf{A}$

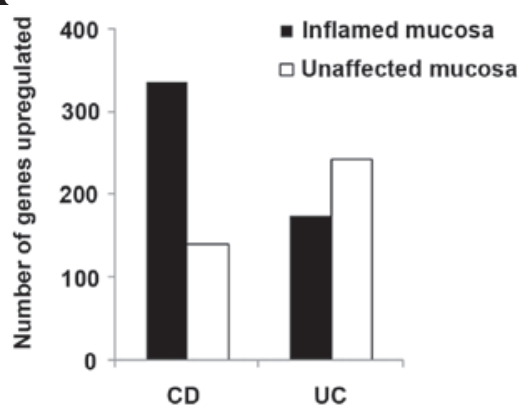

B

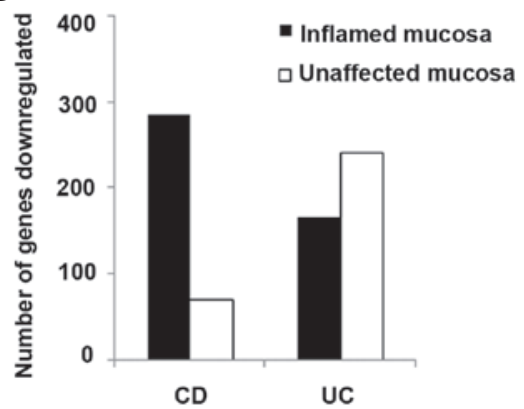

Figure 1. Number of differentially expressed genes in the inflamed and unaffected colon mucosa from patients with inflammatory bowel disease. Only genes with $\geq 3$-fold change in expression, as compared with healthy controls, were included. (A) Number of genes that were upregulated in the inflamed and unaffected colon mucosa from patients with CD and UC. (B) Number of genes that were downregulated in the inflamed and unaffected colon mucosa from patients with $\mathrm{CD}$ and UC. CD, Crohn's disease; UC, ulcerative colitis.

(TAC) software 2.0. Gene Ontology (GO) analyses to assess the functions of genes were performed using the Database for Annotation, Visualization and Integrated Discovery (http://david. abcc.ncifcrf.gov/). Pathway analyses were performed using GenMAPP ( http://www.genmapp.org). The Student's t-test was performed for RT-qPCR data analysis. $\mathrm{P}<0.05$ was considered to indicate a statistically significant difference.

\section{Results}

Large numbers of genes with altered expression patterns are detected in the unaffected and inflamed colon mucosa of patients with mild CD and UC. In inflamed colon biopsies, 620 genes (upregulated, 334; downregulated, 174) in patients with $\mathrm{CD}$ and 339 genes (upregulated, 174; downregulated, 165 ) in patients with UC had $\geq 3$-fold change in expression, as compared with the healthy controls. In addition, a large number of genes with $\geq 3$-fold change, as compared with colon biopsies from normal controls, were identified in the unaffected colon biopsies from patients with CD (139 genes upregulated and 71 genes downregulated) and UC (243 genes upregulated and 240 genes downregulated) (Fig. 1). The number of genes with altered expression levels was greater in the inflamed colon mucosa, as compared with the unaffected colon mucosa, in patients with $\mathrm{CD}$ (upregulated genes, 334 vs. 139, respectively; downregulated genes, 286 vs. 71, respectively). However, the number of genes with altered expression levels was greater in the unaffected colon mucosa, as compared with the inflamed colon mucosa, in patients with UC (upregulated genes, 243 vs. 174, respectively; downregulated genes, 240 vs. 165 , respectively). These results suggest that the abnormalities at the molecular level were not limited to the endoscopic lesions derived from the colons of patients with UC.

Gene expression patterns in the inflamed and unaffected colon mucosa from patients with mild $C D$ and UC are similar. In order to further analyze the differences in the gene expression patterns between the inflamed and unaffected colon mucosa from patients with mild IBD, the intensity of genes with altered expression from inflamed and unaffected colon biopsies was investigated. The differentially expressed genes were clustered and heat maps were generated. The intensity of the color on the heat maps corresponds to the extent of gene expression

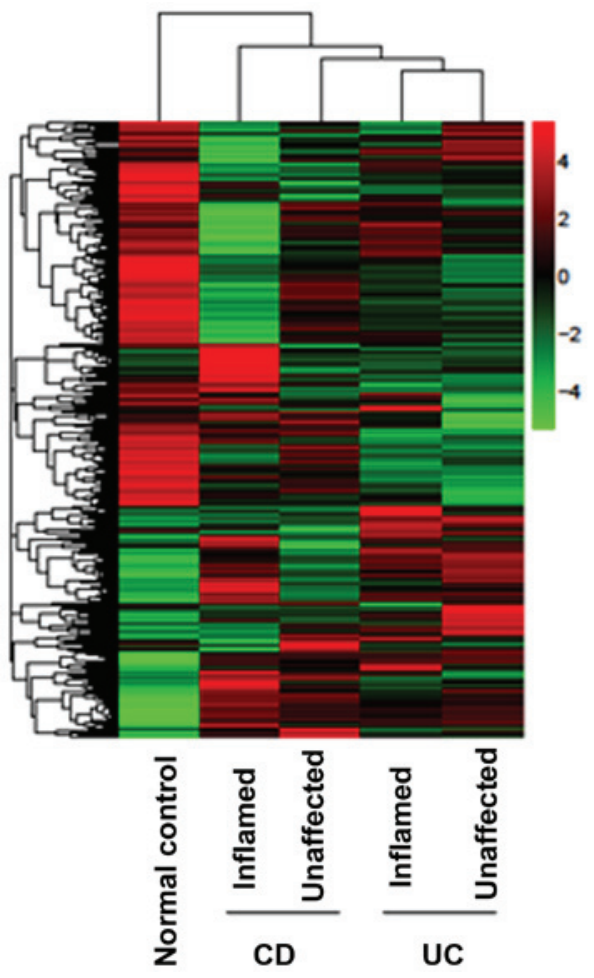

Figure 2. Heat map of gene expression alterations in the inflamed and unaffected colon mucosa from patients with $\mathrm{CD}$ and UC, as compared with healthy controls. CD, Crohn's disease; UC, ulcerative colitis.

alterations. The heat map demonstrated that the expression profiles for the inflamed and unaffected colon mucosa were overlapping, in particular for the UC group (Fig. 2).

Molecular functions and pathways associated with altered transcripts overlap in the inflamed and unaffected colon mucosa from patients with mild IBD. GO analyses of the altered genes in the inflamed and unaffected colon mucosas from patients with CD and UC were conducted. The most prominent molecular functions of the altered genes in the inflamed mucosa of patients with CD included roles in the immune response, extracellular region and nucleus, whereas in the unaffected mucosa of $\mathrm{CD}$ patients, they were the immune response, antigen binding and complement activation. These 
Table I. Molecular functions of the associated genes with altered expression in inflamed and unaffected colon mucosa from patients with inflammatory bowel disease.

\begin{tabular}{|c|c|c|c|c|}
\hline \multirow[b]{2}{*}{$\begin{array}{l}\text { Name of molecular } \\
\text { function }\end{array}$} & \multicolumn{2}{|c|}{ Crohn's disease } & \multicolumn{2}{|c|}{ Ulcerative colitis } \\
\hline & $\begin{array}{l}\text { Inflamed mucosa } \\
\text { P-value }\end{array}$ & $\begin{array}{l}\text { Unaffected mucosa } \\
\text { P-value }\end{array}$ & $\begin{array}{l}\text { Inflamed mucosa } \\
\text { P-value }\end{array}$ & $\begin{array}{l}\text { Unaffected mucosa } \\
\text { P-value }\end{array}$ \\
\hline $\begin{array}{l}\text { Immune response } \\
(\mathrm{GO}: 0006955)\end{array}$ & $9.05 \mathrm{E}-13$ & $2.54 \mathrm{E}-15$ & $1.02 \mathrm{E}-16$ & $6.56 \mathrm{E}-13$ \\
\hline $\begin{array}{l}\text { Complement activation } \\
\text { (GO:0006958) }\end{array}$ & $1.41 \mathrm{E}-05$ & $7.81 \mathrm{E}-11$ & 7.92E-10 & $1.41 \mathrm{E}-05$ \\
\hline $\begin{array}{l}\text { Antigen binding } \\
(\mathrm{GO}: 0003823)\end{array}$ & $1.85 \mathrm{E}-05$ & $8.82 \mathrm{E}-13$ & $6.25 \mathrm{E}-05$ & $1.63 \mathrm{E}-04$ \\
\hline $\begin{array}{l}\text { Extracellular matrix } \\
(\mathrm{GO}: 0031012)\end{array}$ & N/A & N/A & $1.54 \mathrm{E}-04$ & 5.23E-04 \\
\hline $\begin{array}{l}\text { DNA binding } \\
(\mathrm{GO}: 0003677)\end{array}$ & $\mathrm{N} / \mathrm{A}$ & $\mathrm{N} / \mathrm{A}$ & $1.24 \mathrm{E}-04$ & $1.04 \mathrm{E}-04$ \\
\hline $\begin{array}{l}\text { Extracellular region } \\
(\mathrm{GO}: 0005576)\end{array}$ & $6.25 \mathrm{E}-08$ & $4.67 \mathrm{E}-04$ & $3.54 \mathrm{E}-14$ & $2.98 \mathrm{E}-12$ \\
\hline $\begin{array}{l}\text { Nucleus } \\
(\mathrm{GO}: 0005634)\end{array}$ & $4.00 \mathrm{E}-07$ & $\mathrm{~N} / \mathrm{A}$ & $1.73 \mathrm{E}-04$ & $1.34 \mathrm{E}-06$ \\
\hline $\begin{array}{l}\text { Innate immune response } \\
\text { (GO:0045087) }\end{array}$ & $\mathrm{N} / \mathrm{A}$ & $3.24 \mathrm{E}-05$ & $2.33 \mathrm{E}-05$ & $\mathrm{~N} / \mathrm{A}$ \\
\hline $\begin{array}{l}\text { Extracellular space } \\
(\mathrm{GO}: 0005615)\end{array}$ & 5.11E-06 & N/A & 7.33E-12 & N/A \\
\hline $\begin{array}{l}\text { Transcription, DNA-dependent } \\
\text { (GO:0006351) }\end{array}$ & $8.48 \mathrm{E}-05$ & $\mathrm{~N} / \mathrm{A}$ & $5.00 \mathrm{E}-04$ & 4.68E-06 \\
\hline $\begin{array}{l}\text { Chemokine activity } \\
\text { (GO:0008009) }\end{array}$ & 0.000144 & 0.00157 & $7.82 \mathrm{E}-05$ & 0.00172 \\
\hline
\end{tabular}

Table II. Pathways of associated genes with altered expression in inflamed and unaffected colon mucosa from patients with inflammatory bowel disease.

\begin{tabular}{|c|c|c|c|c|}
\hline \multirow[b]{2}{*}{ Name of pathway } & \multicolumn{2}{|c|}{ Crohn's disease } & \multicolumn{2}{|c|}{ Ulcerative colitis } \\
\hline & $\begin{array}{l}\text { Inflamed mucosa } \\
\text { P-value }\end{array}$ & $\begin{array}{l}\text { Unaffected mucosa } \\
\text { P-value }\end{array}$ & $\begin{array}{l}\text { Inflamed mucosa } \\
\text { P-value }\end{array}$ & $\begin{array}{l}\text { Unaffected mucosa } \\
\text { P-value }\end{array}$ \\
\hline $\begin{array}{l}\text { Staphylococcus aureus infection } \\
\text { (hsa05150) }\end{array}$ & 8.88E-07 & 0.004322 & $3.22 \mathrm{E}-08$ & 4.64E-06 \\
\hline $\begin{array}{l}\text { Asthma } \\
(\text { hsa05310) }\end{array}$ & $2.34 \mathrm{E}-06$ & $\mathrm{~N} / \mathrm{A}$ & $3.03 \mathrm{E}-05$ & N/A \\
\hline $\begin{array}{l}\text { Mineral absorption } \\
\text { (hsa04978) }\end{array}$ & $6.93 \mathrm{E}-06$ & $6.11 \mathrm{E}-09$ & 0.000134 & $8.12 \mathrm{E}-06$ \\
\hline $\begin{array}{l}\text { Olfactory transduction } \\
\text { (hsa04740) }\end{array}$ & $3.97 \mathrm{E}-05$ & $\mathrm{~N} / \mathrm{A}$ & N/A & 0.000358 \\
\hline $\begin{array}{l}\text { Starch and sucrose metabolism } \\
\text { (hsa00500) }\end{array}$ & $8.49 \mathrm{E}-05$ & N/A & N/A & 0.001897 \\
\hline $\begin{array}{l}\text { Protein digestion and absorption } \\
\text { (hsa04974) }\end{array}$ & 0.000136 & 0.000447 & $3.45 \mathrm{E}-08$ & $1.28 \mathrm{E}-08$ \\
\hline $\begin{array}{l}\text { Retinol metabolism } \\
\text { (hsa00830) }\end{array}$ & $3.97 \mathrm{E}-05$ & N/A & $1.64 \mathrm{E}-06$ & $6.25 \mathrm{E}-06$ \\
\hline $\begin{array}{l}\text { Linoleic acid metabolism } \\
\text { (hsa00591) }\end{array}$ & N/A & 0.000152 & $4.58 \mathrm{E}-06$ & $3.98 \mathrm{E}-05$ \\
\hline $\begin{array}{l}\text { Chemokine signaling pathway } \\
\text { (hsa04062) }\end{array}$ & N/A & 0.000228 & $\mathrm{~N} / \mathrm{A}$ & $\mathrm{N} / \mathrm{A}$ \\
\hline
\end{tabular}



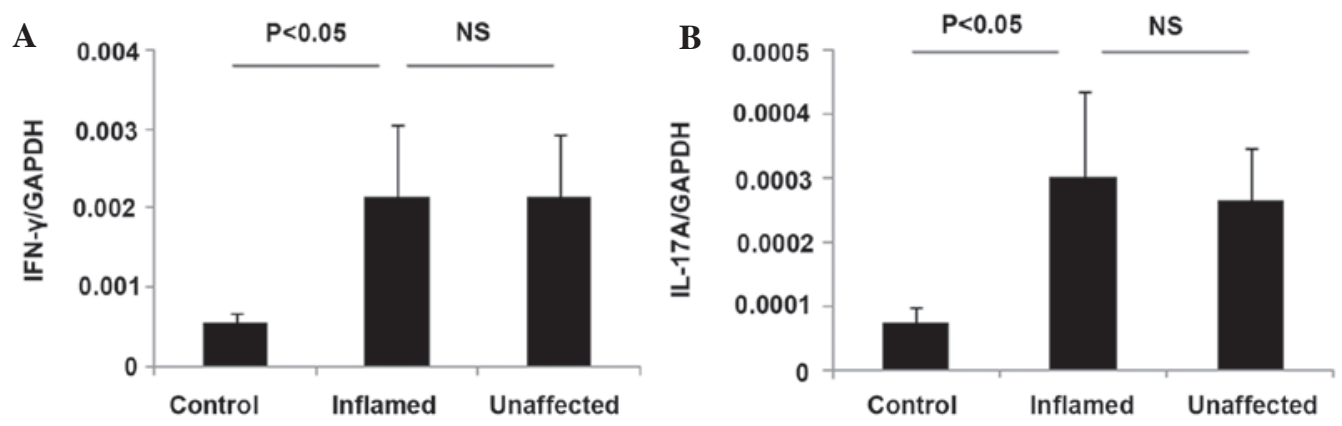

Figure 3. Inflammatory cytokine levels in the inflamed and unaffected colon mucosa from patients with UC. The mRNA expression levels of (A) INF- $\gamma$ and (B) IL-17A in the inflamed and unaffected colon mucosa from patients with UC. Data are presented as the mean \pm standard deviation. NS, no significant difference; UC, ulcerative colitis; IFN, interferon; IL, interleukin; GAPDH, glyceraldehyde 3-phosphate dehydrogenase.

results suggested that there was an overlap in the molecular functions of the altered transcripts between the inflamed and unaffected colon mucosa of patients with CD.

The most prominent molecular functions of the altered genes detected in the inflamed mucosa of patients with UC included roles in the immune response, extracellular region and extracellular space, whereas in the unaffected mucosa of patients with $\mathrm{CD}$, they were the immune response, extracellular region and nucleus; thus suggesting that there was marked similarity and overlap in the molecular functions of the transcripts between the inflamed and unaffected colon mucosa in patients with UC (Table I).

The pathways associated with these transcripts were also investigated and the common pathways of the altered genes in the inflamed and unaffected colon mucosa from the CD group included: Staphylococcus aureus infection, mineral absorption and protein digestion and absorption. Conversely, the common pathways for the altered genes in the inflamed and unaffected colon mucosa from the UC group included: $S$. aureus infection, asthma, mineral absorption, protein digestion and absorption, retinol metabolism and linoleic acid metabolism (Table II). These results suggested that there were similarities in the molecular functions associated with the altered transcripts between the inflamed and unaffected colon mucosa from $\mathrm{CD}$ and $\mathrm{UC}$ patients.

Inflammatory cytokines are elevated in the inflamed and unaffected colon mucosa from patients with UC. Alterations in the expression levels of inflammatory cytokines in the colon mucosa is a key pathological characteristic of IBD, and it has been associated with disease activity and mucosal inflammation (20-22). The present study investigated the mRNA expression levels of IFN- $\gamma$ and IL-17 in inflamed and unaffected colon biopsies from patients with UC using RT-qPCR. The CD patients were not analyzed as there were insufficient CD patients for conducting RT-qPCR analyses. The levels of IFN- $\gamma$ and IL-17 were comparably elevated in the inflamed and unaffected colon mucosa from patients with UC (Fig. 3), and were significantly different from the control $(\mathrm{P}<0.05$; Fig. 3$)$.

\section{Discussion}

The cause of relapses in patients with CD and UC are largely unknown, which may be due to the lack of a sensitive method for monitoring mucosal inflammation before an endoscopic abnormality becomes apparent (2-4). The incidence of endoscopic recurrence in patients with $\mathrm{CD}$ at 1 year following curative resection is as high as $75 \%$ (20). Subjective symptoms are not reliable indicators of disease activity, whereas endoscopy is an objective tool (16). However, the present study demonstrated that endoscopic observations may be insufficient for detecting an underlying impairment of the gut mucosa, since pathological molecular alterations occurred in the inflamed and unaffected colon mucosa of patients with mild IBD.

The present study demonstrated that large numbers of genes were abnormally expressed (either upregulated or downregulated) in patients with mild IBD, as compared with normal controls. These results indicated that the evaluation of gene expression profiles may be considered a sensitive and reliable method for detecting mucosal inflammation. Furthermore, the present study demonstrated that there were similarities in the gene expression alterations and inflammatory cytokine expression levels between the inflamed and unaffected mucosa from patients with IBD, in particular in patients with UC. This finding suggested that mucosal inflammation may not be limited to endoscopic lesions in the gut, and that molecular abnormalities may better diagnose an impairment of intestinal homeostasis and subclinical intestinal inflammation. Consistent with these results, a previous study demonstrated that there were marked overlaps in the gene expression alterations between the small bowel proximal to the pouch and the pouch itself in patients with UC following restorative proctocolectomy (23).

The molecular functions of the altered genes associated with IBD in the present study fell into three main categories: Inflammation, nutrition absorption and cell structure. Therefore, the altered expression of inflammation-associated genes may be the initial abnormality in the pathogenesis of IBD, which is supported by the finding that IBD is a disease caused by an unbalanced immune response to intestinal commensal organisms (24-26). However, it is also possible that abnormal cell structure may trigger the impairment of barrier function prior to the induction of an unbalanced immune response to the gut microbiota (27). The precise associations among inflammation, nutrition absorption and cell structure require further investigation.

It was demonstrated that, as well as nutrition digestion, absorption and metabolism, S. aureus infection was overrepresented in the inflamed and unaffected colon mucosa from 
CD and UC patients. A case of a hospitalized CD patient with an intestinal methicillin-resistant $S$. aureus infection has been previously reported (28). In addition, a previous study demonstrated that $S$ aureus infection increased and was associated with the risk of mortality in hospitalized patients with IBD (29). However, none of the patients enrolled in the present study were hospitalized nor did they exhibit clinical manifestations of a $S$. aureus infection. Therefore, the significance of the $S$. aureus infection pathway as a tool for predicting the occurrence of a relapse in patients with IBD requires further investigation. In addition, it may be useful to screen patients with IBD for $S$. aureus infections.

The management of IBDs often depends on the disease severity (2); however, the assessment of disease activity may be critical for the design of an optimal therapeutic strategy in order to prevent the recurrence of IBDs. The stopping or tapering of medication for IBD is usually objective and dependant on the experience of the individual physician. The present study demonstrated that gene expression profile analyses may be considered a sensitive and reliable method for the detection of subclinical mucosal inflammation in recurrent IBD patients with mild symptoms. Abnormal gene expression profiles in patients with normal endoscopic findings may predict the occurrence of relapses after treatment has been stopped or tapered. In addition, for such patients, the maintenance of treatment may be considered. Therefore, the results of the present study may be of value in clinical practice regarding the diagnosis and development of therapeutic strategies for patients with IBDs. One limitation of the present study was the relatively small size of the cohort due to economical reasons. Therefore, the results require verification using larger groups of patients.

In conclusion, the present study analyzed the gene expression profiles of inflamed and unaffected colon mucosa from patients with mild CD and UC. Marked alterations in the gene expression profiles of these patients were identified, and there was marked similarity and overlap in the gene expression alterations that occurred between the inflamed and unaffected mucosa of patients with UC. The results of the present study suggested that gene expression profiling may be considered a more sensitive tool, as compared with an endoscopic evaluation, for the detection of a colon mucosa impairment in patients with IBDs, in particular in patients with UC.

\section{Acknowledgements}

The authors would like to thank Shanghai South Gene Technology (Shanghai, China) for assistance with the microarray study and bioinformatics analysis. The present study was supported by the National Natural Science Foundation of China (grant no. 81370510) and the Shanghai Committee of Science and Technology (grant no. 13140902000).

\section{References}

1. Orlando A, Mocciaro F, Renna S, Scimeca D, Rispo A, Lia Scribano M, Testa A, Aratari A, Bossa F, Tambasco R, et al: Early post-operative endoscopic recurrence in Crohn's disease patients: data from an Italian Group for the study of inflammatory bowel disease (IG-IBD) study on a large prospective multicenter cohort. J Crohns Colitis 8: 1217-1221, 2014.
2. Pineton de Chambrun GP and Sandborn WJ: IBD in 2011: Advances in IBD management-towards a tailored approach. Nat Rev Gastroenterol Hepatol 9: 70-72, 2012.

3. Martin TD, Chan SS and Hart AR: environmental factors in the relapse and recurrence of inflammatory bowel disease: A review of the literature. Dig Dis Sci 60: 1396-1405, 2015.

4. Spooren CE, Pierik MJ, Zeegers MP, Feskens EJ, Masclee AA and Jonkers DM: Review article: The association of diet with onset and relapse in patients with inflammatory bowel disease. Aliment Pharmacol Ther 38: 1172-1187, 2013.

5. Schaffer T, Schoepfer AM and Seibold F; Swiss IBD Cohort Study Group: Serum ficolin-2 correlates worse than fecal calprotectin and CRP with endoscopic Crohn's disease activity. J Crohns Colitis 8: 1125-1132, 2014.

6. Minar P, Haberman Y, Jurickova I, Wen T, Rothenberg ME, Kim MO, Saeed SA, Baldassano RN, Stephens M, Markowitz J, et al: Utility of neutrophil Fc $\gamma$ receptor I (CD64) index as a biomarker for mucosal inflammation in pediatric Crohn's disease. Inflamm Bowel Dis 20: 1037-1048, 2014.

7. Däbritz J, Bonkowski E, Chalk C, Trapnell BC, Langhorst J, Denson LA and Foell D: Granulocyte macrophage colony-stimulating factor auto-antibodies and disease relapse in inflammatory bowel disease. Am J Gastroenterol 108: 1901-1910, 2013.

8. Naismith GD, Smith LA, Barry SJ, Munro JI, Laird S, Rankin K, Morris AJ, Winter JW and Gaya DR: A prospective evaluation of the predictive value of faecal calprotectin in quiescent Crohn's disease. J Crohns Colitis 8: 1022-1029, 2014.

9. Foell D, Wittkowski H and Roth J: Monitoring disease activity by stool analyses: From occult blood to molecular markers of intestinal inflammation and damage. Gut 58: 859-868, 2009.

10. Masclee GM, Penders J, Jonkers DM, Wolffs PF and Pierik MJ: Is clostridium difficile associated with relapse of inflammatory bowel disease? Results from a retrospective and prospective cohort study in the Netherlands. Inflamm Bowel Dis 19: 2125-2131, 2013.

11. Sorrentino D, Nash P, Viladomiu M, Hontecillas R and Bassaganya-Riera J: Stopping anti-TNF agents in patients with Crohn's disease in remission: Is it a feasible long-term strategy? Inflamm Bowel Dis 20: 7570-766, 2014.

12. Dai C, Liu WX, Jiang M and Sun MJ: Mucosal healing did not predict sustained clinical remission in patients with ibd after discontinuation of one-year infliximab therapy. PLoS One 9: e110797, 2014

13. Kennedy NA, Kalla R, Warner B, Gambles CJ, Musy R, Reynolds S, Dattani R, Nayee H, Felwick R, Harris R, et al: Thiopurine withdrawal during sustained clinical remission in inflammatory bowel disease: Relapse and recapture rates, with predictive factors in 237 patients. Aliment Pharmacol Ther 40: 1313-1323, 2014.

14. Regueiro M, Kip KE, Baidoo L, Swoger JM and Schraut W: Postoperative therapy with infliximab prevents long-term Crohn's disease recurrence. Clin Gastroenterol Hepatol 12: 1494-1502, 2014.

15. Farkas K, Lakatos PL, Nagy F, Szepes Z, Miheller P, Papp M, Palatka K, Bálint A, Bor R, Wittmann T and Molnár T: Predictors of relapse in patients with ulcerative colitis in remission after one-year of infliximab therapy. Scand J Gastroenterol 48: 1394-1398, 2013.

16. Keyashian K: Does endoscopic assessment of mucosal healing affect IBD management? Dig Dis Sci 59: 2351-2353, 2014.

17. Mańkowska-Wierzbicka D, Swora-Cwynar E, Poniedziałek B, Adamski Z, Dobrowolska A and Karczewski J: Usefulness of selected laboratory markers in ulcerative colitis. Eur Cytokine Netw: Oct 13, 2015 (Epub ahead of print).

18. Monteleone G, Di Sabatino A, Ardizzone S, Pallone F, Usiskin K, Zhan X, Rossiter G and Neurath MF: Impact of patient characteristics on the clinical efficacy of mongersen (GED-0301), an oral Smad7 antisense oligonucleotide, in active Crohn's disease. Aliment Pharmacol Ther: Jan 13, 2016 (Epub ahead of print).

19. Livak KJ and Schmittgen TD: Analysis of relative gene expression data using real-time quantitative PCR and the 2(-Delta Delta C(T)) Method. Methods 25: 402-408, 2001.

20. Neurath MF: Cytokines in inflammatory bowel disease. Nat Rev Immunol 14: 329-342, 2014.

21. Hundorfean G, Neurath MF and Mudter J: Functional relevance of T helper 17 (Th17) cells and the IL-17 cytokine family in inflammatory bowel disease. Inflamm Bowel Dis 18: 180-186, 2012.

22. Aine B, Grainne L and Kate K: Transcriptional profiling of the colonic mucosa and epithelial cells of patients with acutely active ulcerative colitis. Inflamm Bowel Dis (Suppl 1): S10-S11, 2014. 
23. Yanai H, Ben-Shachar S, Baram L, Elad H, Gitstein G, Brazowski E, Tulchinsky H, Pasmanik-Chor M and Dotan I: Gene expression alterations in ulcerative colitis patients after restorative proctocolectomy extend to the small bowel proximal to the pouch. Gut 64: 756-764, 2015

24. Abraham $\mathrm{C}$ and Medzhitov R: Interactions between the host innate immune system and microbes in inflammatory bowel disease. Gastroenterology 140: 1729-1737, 2011.

25. MacDonald TT, Biancheri P, Sarra M and Monteleone G: What's the next best cytokine target in IBD? Inflamm Bowel Dis 18: 2180-2189, 2012

26. Cader MZ and Kaser A: Recent advances in inflammatory bowel disease: Mucosal immune cells in intestinal inflammation. Gut 62: 1653-1664, 2013.
27. Henderson P, van Limbergen JE, Schwarze J and Wilson DC: Function of the intestinal epithelium and its dysregulation in inflammatory bowel disease. Inflamm Bowel Dis 17: 382-395, 2011.

28. Nguyen GC, Patel H and Chong RY: Increased prevalence of and associated mortality with methicillin-resistant Staphylococcus aureus among hospitalized IBD patients. Am J Gastroenterol 105: 371-377, 2010.

29. Bryant RV, Winer S, Travis SP and Riddell RH: Systematic review: Histological remission in inflammatory bowel disease. Is 'complete' remission the new treatment paradigm? An IOIBD initiative. J Crohns Colitis 8: 1582-1597, 2014. 